\title{
The effect of high-speed Shinkansen train draughts in tunnels on current collection performance
}

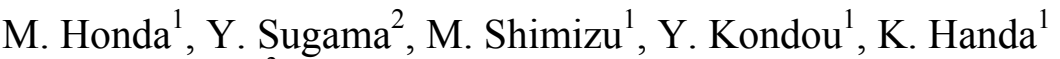 \\ $\&$ T. Mitsumoji ${ }^{3}$ \\ ${ }^{1}$ Power Supply Technology Division, \\ Railway Technical Research Institute, Japan \\ ${ }^{2}$ East Japan Railway Company, Japan \\ ${ }^{3}$ Railway Dynamics Division, \\ Railway Technical Research Institute, Japan
}

\begin{abstract}
It is well-known that the wind speed affecting the pantograph is stronger in tunnels than in the open air on the Shinkansen line. Therefore, the authors measured wind speed, wind direction, dynamic behavior of the overhead contacts line and metal fittings when the Shinkansen train ran through a tunnel at high-speed. This paper discusses the influence of the air flow in a tunnel caused by a high-speed train on current collection performance and the overhead contacts lines. Further, the aerodynamic upward force of the pantograph was estimated on the basis of the measured results. Finally, using the motion simulation of a pantograph and overhead contacts line, their dynamic characteristics at high-speed were evaluated.

Keywords: electric railway, current collection, overhead contact line, tunnel, train draughts, upward force of the pantograph.
\end{abstract}

\section{Introduction}

The upward force of a pantograph increases in a tunnel for the reason that wind speed affecting the pantograph is stronger in the tunnel than in the open air [1]. In addition, the wind speed in the tunnel tends to be strong because the cross section of tunnels in Japan is smaller than that in other countries. Therefore, 
current collection performance in tunnels is one of the indicators to evaluate the safety of the current collecting facilities. The discussion taking account of the train wind in a tunnel is necessary to show the issues to be improved factor and technical margin for a higher speed train. Recently, the Shinkansen train velocity has been faster and faster. We measured wind speed and wind direction near the current collecting system, displacement of overhead contact lines and metal fittings, and stress of these in the tunnel. Using the measurement data, we show how the wind speed and wind direction of train wind in the tunnel affects the strain and uplift of the lines. In addition, the aerodynamic upward force of pantograph is estimated on the basis of wind speed blowing parallel to the track line in the tunnel. Further, using the dynamic simulation of pantograph-catenary system, dynamic characteristics of the lines and metals at high-speed are evaluated.

\section{Measurement method and condition of wind speed, direction, and behavior of overhead contact wire}

\subsection{Measurement condition}

Table 1 reports the conditions of the tunnel and overhead contact line. Fig. 1 shows the cross section of the tunnel A. Tunnel A is relatively long. It contains a meeting area of up and down trains. Catenary system adopts high-speed heavy compound catenary, of which contact wire uses GT-PHC110. The measurement area is chosen around the midpoint of the tunnel where up and down trains have possibilities to meet. Tunnel B is relatively short. It doesn't contain a meeting area of up and down trains. The catenary system adopts a normal heavy compound catenary, of which contact wire uses GT-Sn170. The measurement area is chosen around the area where air pressure wave which is generated when a train enters in the tunnel, meets a train after reflecting at the end of the tunnel.

Table 2 reports the conditions of passage train sets. There are train sets consisting of standard-section vehicles and others consisting of small-section vehicles coupled with standard-section vehicles. The measurement railway track is the outbound one. In the case of coupled train, the head vehicle is the smallsection one.

\subsection{Measurement method}

Fig. 2 shows the measurement system. Many sensors were attached to various parts of overhead contact line and facilities. The measured data are collected into the Auto-collected Device installed on hinged cantilever. We measured the wind speed, and wind direction (400mm above the contact wire). Also the displacement, stress, and acceleration of lines and metal fittings were measured. The vertical and horizontal displacements at the hanger position were calculated by integration of acceleration. 
Table 1: The conditions of the tunnel and catenary system.

\begin{tabular}{|c|c|c|c|}
\hline \multicolumn{2}{|c|}{ Name } & Tunnel A & Tunnel B \\
\hline \multicolumn{2}{|c|}{ Length } & $9,730 \mathrm{~m}$ & $2,620 \mathrm{~m}$ \\
\hline \multicolumn{2}{|c|}{ Measurement position (from entrance) } & $4,051 \mathrm{~m}$ & $743 \mathrm{~m}$ \\
\hline \multicolumn{2}{|c|}{ Cross section } & $63.4 \mathrm{~m}^{2}$ & $63.4 \mathrm{~m}^{2}$ \\
\hline \multicolumn{2}{|c|}{ Catenary system } & $\begin{array}{l}\text { high-speed heavy } \\
\text { compound catenary }\end{array}$ & $\begin{array}{c}\text { normal heavy } \\
\text { compound catenary }\end{array}$ \\
\hline \multirow{3}{*}{$\begin{array}{l}\text { Kinds of lines } \\
\text { (tension) }\end{array}$} & Messenger $(\mathrm{Me})$ & St180 (21.6kN) & $\mathrm{St} 180(24.5 \mathrm{kN})$ \\
\hline & Auxiliary $(\mathrm{Ax})$ & PH-Ag150 (12.7kN) & PH-Ag150 (9.8kN) \\
\hline & Contact wire $(\mathrm{Tr})$ & $\begin{array}{c}\text { GT-PHC110 } \\
(19.6 \mathrm{kN})\end{array}$ & GT-Sn170 (19.6kN) \\
\hline \multicolumn{2}{|c|}{ Span } & $45 \mathrm{~m}$ & $45 \mathrm{~m}$ \\
\hline
\end{tabular}

Table 2: The conditions of the train sets.

\begin{tabular}{|c|c|c|c|c|c|}
\hline \multirow{2}{*}{$\begin{array}{c}\text { Train } \\
\text { set }\end{array}$} & Car cross-section & \multicolumn{4}{|c|}{ Distance from train head [m] } \\
\cline { 3 - 6 } & (Number of pantograph) & No. 1 & No. 2 & No. 3 & No. 4 \\
\hline A & Standard (1) & 180 & - & - & - \\
\hline B & Standard (2) & 124 & 173 & - & - \\
\hline C & Small (2)+standard (1) & 43 & 103 & 308 & - \\
\hline D & Small (2)+standard (2) & 43 & 103 & 252 & 301 \\
\hline E & Small (1)+standard (1) & 108 & 329 & - & - \\
\hline
\end{tabular}

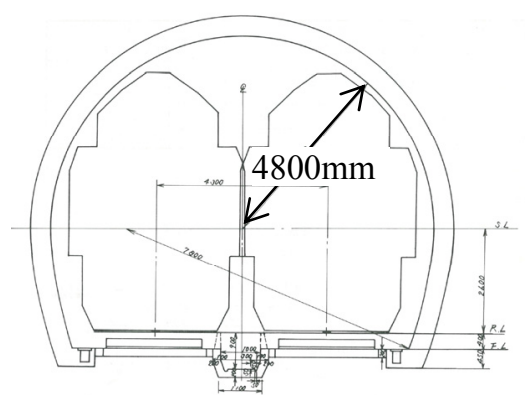

Figure 1: The cross section of the tunnel A.

\section{Wind speed when the train passes in the tunnel}

\subsection{Wind speed parallel to track line direction}

\subsubsection{Characteristic of wind speed and direction}

Fig. 3 shows two examples of chart of wind speed, wind direction, and contact wire uplift at supporting point. They are measured when the train type D runs at $270 \mathrm{~km} / \mathrm{h}$ in the tunnel A. In the paper, we call "Proceeding train" in cases when 
the train is running on the outbound line, and call "Oncoming train" in cases when the train is running on the inbound line.

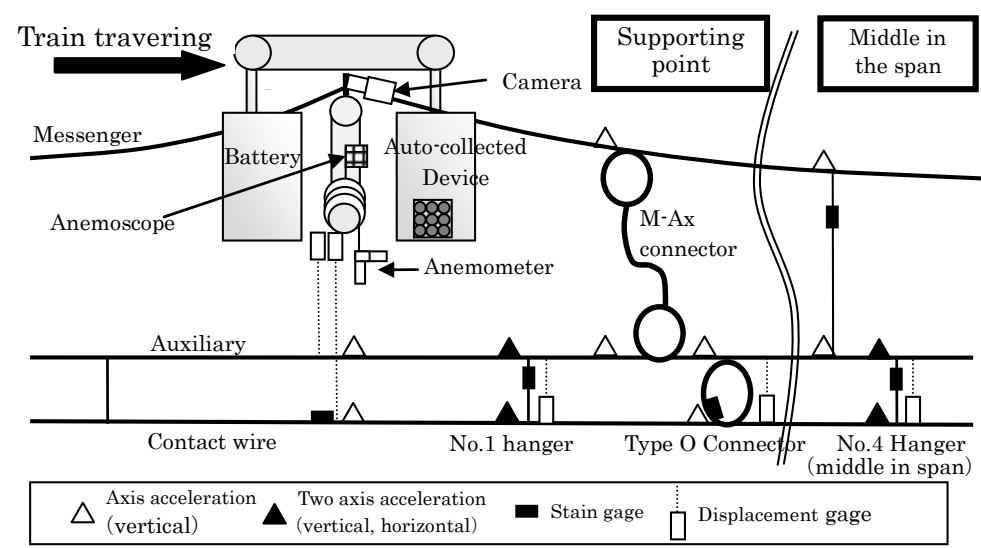

Figure 2: The outline of measurement system.

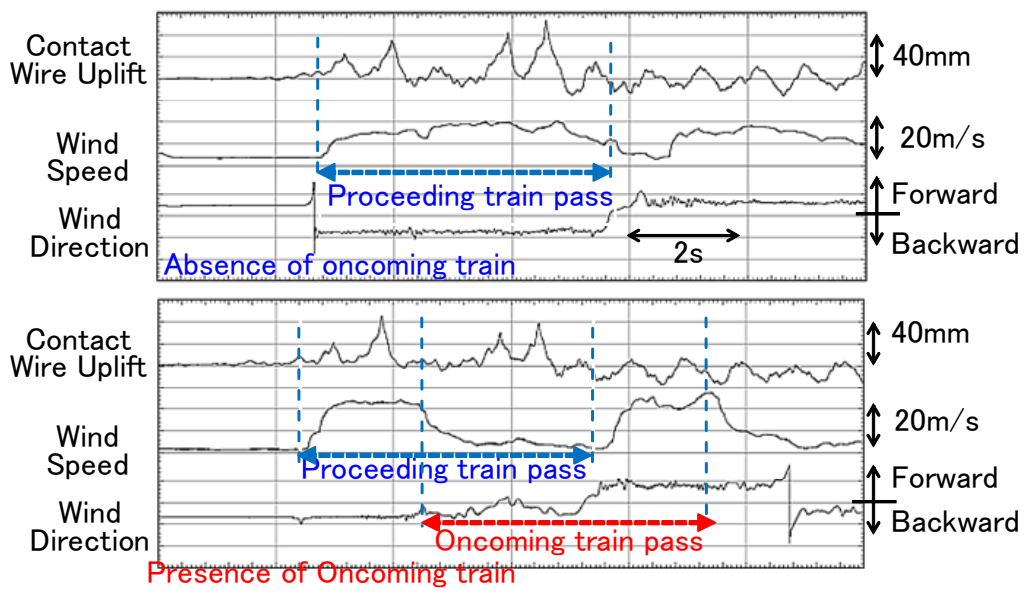

Figure 3: The examples of the wind speed and the direction parallel to track.

When there is no oncoming train, wind direction varies simple. The wind blows in the direction of train running before and after the train passes through the measurement point. On the other hand, the wind direction is opposite during the train passes through there. In addition, there is a tendency that the wind speed is stronger at the rear of the train. When an oncoming train exists, wind direction varies depending on its position. The wind speed is larger than that in the case of absence of the oncoming train. Moreover, when both of the proceeding train and the oncoming train pass through the measurement point at the same time, the wind speed decreases because of mutual cancelling. 
The wind speed when the proceeding train passes through the measurement point is stronger in the case of presence of the oncoming train than that in the case of its absence. However, too excessive wind speed and complicated change of wind direction aren't observed.

\subsubsection{Maximum wind speed parallel to the track line direction}

Fig. 4 shows the maximum wind speed parallel to track line when the proceeding train passes through the measurement point. The approximation straight lines passing through the origin are shown in fig. 4, and also in the later figures of train velocity characteristics of the wind speed. The wind direction is opposite to train running direction. Fig. 4(a) shows the comparison of wind speed under the presence of oncoming train and that under the absence in tunnel A. There is a tendency that the wind speed under the presence of the oncoming train is larger than that under its absence. Fig. 4(b) shows the maximum wind speed in the tunnel B. Although there is no oncoming train, it is slightly larger than that under absence of oncoming train in the tunnel A. This reason seems to be the propagation of pressure wave in the tunnel.

Fig. 5 shows a wind speed at the pantograph position which is calculated by one-dimensional air flow simulation for the train type A running with $270 \mathrm{~km} / \mathrm{h}$ in the tunnel A [2]. This simulation is carried out by RTRI Heat and Air Flow Analysis Lab. When the proceeding train enters the tunnel, the pressure wave is generated. It reflects at the tunnel entrance and the exit repeatedly. In case the train runs in the tunnel A with $270 \mathrm{~km} / \mathrm{h}$, the train goes through the measurement point after it meets with the pressure wave reflected at the tunnel exit. Thus, the wind speed at the pantograph is decreased.

On the other hand, in case the train runs in the tunnel B with $270 \mathrm{~km} / \mathrm{h}$, the train goes through the measurement point before it meets with the pressure wave reflected at the tunnel exit. The meeting point is $250 \mathrm{~m}$ away from the measurement point. Therefore, the wind speed at the head of the train indicates the value before the train meets with the pressure wave reflected at the tunnel exit. Thus, it is considered that the wind speed in the tunnel B is stronger than that in the tunnel A in spite of the same train velocity.

\subsubsection{The head wind speed at the pantograph}

The upward force of the pantograph of the running train is generally proportional to the square of the head wind speed at pantograph. The head wind is parallel to the track line. It is a very important indicator to understand the influence on the current collection performance.

Fig. 6 shows a comparison of the head wind speeds at No. 1 pantographs of various train types in the tunnel $\mathrm{A}$. There is a tendency that the head wind speeds of the trains A, B are stronger than those of the trains C, D. The reason seems to be due to the difference of the ratio of the train cross-sectional area to the tunnel cross-sectional area. It should be noted that the cross sections of the vehicles on which No. 1 pantographs of the trains A, B are installed are the standard size; on the other hand, those of the trains C, D are the small size. In addition, even for the same vehicle cross-section, the head wind speed at No. 1 pantograph of the train A (long distance from the train head to No. 1 pantograph) seems to be 
stronger than that of the train B (short distance). It is considered to be due to the mainstream speed increase by the fact that the longer the distance from the train head to No. 1 pantograph is, the thicker the boundary layer in the vicinity of train surface is.

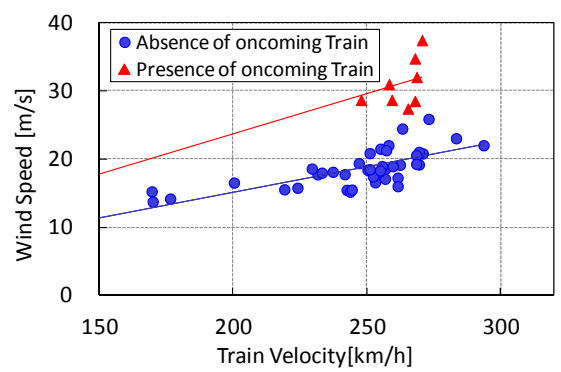

(a) Tunnel A

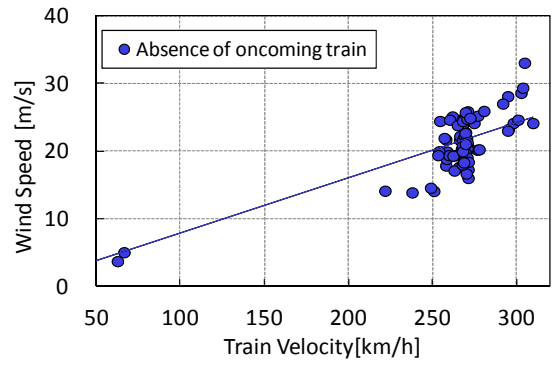

(b) Tunnel B

Figure 4: The maximum wind speed parallel to track line direction (speed against the ground).

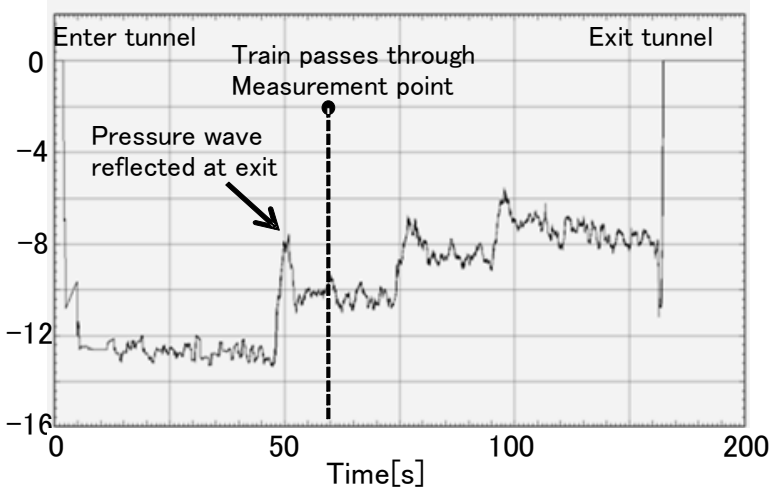

Figure 5: The wind speed at the pantograph calculated by one-dimensional air flow simulation (speed against the ground).

In Tunnel B, the similar results are obtained about the relationship between the head wind speed and the train cross-section, and the relationship between the head wind speed and the distance from the train head to No. 1 pantograph.

\subsection{The wind speeds in the direction orthogonal to track line, and in the vertical direction}

Fig. 7(a) shows the result of wind speed in the direction orthogonal to the track line in the tunnel A. The wind speed tended to be stronger in the case of presence of the oncoming train than that in the case of the absence. The wind blows from the tunnel center to the tunnel wall. 
Fig. 7(b) shows the measured data of wind speed in the vertical direction in the tunnel A. It shows only the upward wind because the upward wind is stronger than the downward one. The maximum wind speed is less than $5 \mathrm{~m} / \mathrm{s}$. There is no correlation between the wind speed and the train velocity. There is also no difference between the presence case and the absence case of the oncoming train.

\section{The wind speed to be considered in the tunnel}

\subsection{The wind speed for the overhead contact line facilities}

Table 3 reports the ratio of wind speed to the train velocity for the overhead contact line facilities. Each ratio is calculated from the slopes of the approximate lines of the measured data in fig. 4 and fig. 7(a). Table 4 reports the ratio of the wind speed to the train velocity to be considered for the overhead contact line facilities when the train passes through the tunnel. Table 4 is prepared based on table 3. It contains some margins. The wind speed for the vertical direction is determined by the measured maximum value $(5 \mathrm{~m} / \mathrm{s})$ because there is no clear characteristic of wind speed against train velocity.

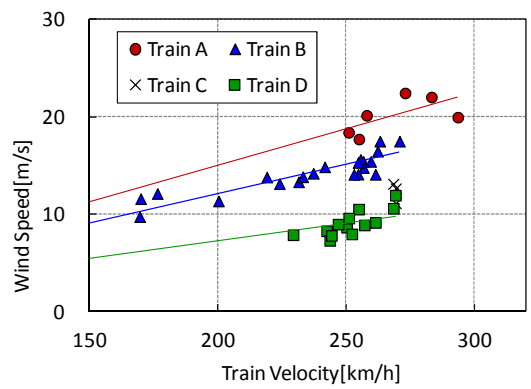

Figure 6: The maximum head wind speed at No. 1 pantograph (speed against the ground).

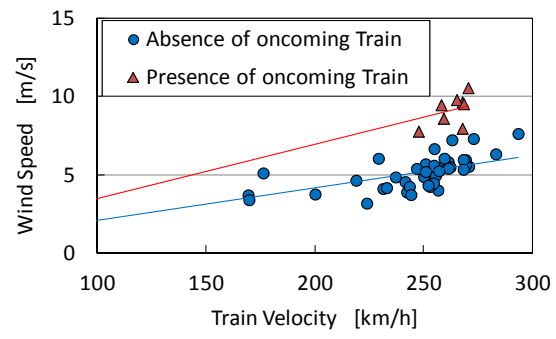

(a) The direction orthogonal to the track line

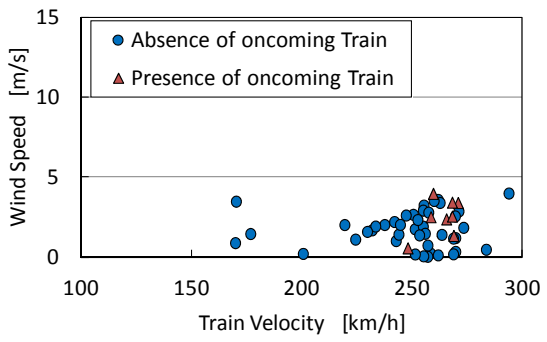

(b) The vertical direction

Figure 7: The maximum wind speed in the direction orthogonal to track line and in the vertical direction (speed against the ground). 
Table 3: The ratio of the wind speed to the train velocity to affect the overhead contact line facilities.

\begin{tabular}{|c|c|c|c|}
\hline \multirow{2}{*}{ Wind direction } & \multirow{2}{*}{ Tunnel } & Oncoming train & $\begin{array}{c}\text { Ratio of wind speed to train } \\
\text { velocity }\end{array}$ \\
\hline \multirow{3}{*}{ Parallel to track line } & \multirow{2}{*}{$\mathrm{A}$} & Absence & 0.27 \\
\cline { 3 - 4 } & $\mathrm{B}$ & Presence & 0.49 \\
\cline { 3 - 4 } & \multirow{2}{*}{ Orthogonal direction } & Absence & 0.29 \\
\cline { 3 - 4 } & & Absence & 0.075 \\
\hline
\end{tabular}

\subsection{Head wind at the pantograph}

As indicated in the chapter 3 , the head wind at the pantograph of the running train is different depending on the presence or absence case of the oncoming train, the train cross-section, and the distance from the train head to No. 1 pantograph.

Table 5 reports the ratio of the head wind speed to the train velocity at all the pantographs in each train set in the tunnel A. Table 6 also reports the similar ratios in the tunnel $\mathrm{B}$. Table 7 reports the summary of the head wind speed to be considered at the pantograph on the running train in the tunnel. It is determined from the measured data at the pantograph position as previously described and the maximum wind speed when the train passes through (table 3 ).

Table 4: The wind speed to be considered for the overhead contact line facilities.

\begin{tabular}{|c|c|c|c|}
\hline Wind direction & $\begin{array}{c}\text { Oncoming } \\
\text { train }\end{array}$ & $\begin{array}{c}\text { Ratio of the } \\
\text { wind speed to } \\
\text { train velocity }\end{array}$ & $\begin{array}{c}\text { Wind speed to be considered } \\
\text { when the train runs with } \\
300 \mathrm{~km} / \mathrm{h}\end{array}$ \\
\hline \multirow{2}{*}{ Parallel to track line } & Absence & 0.3 & $25 \mathrm{~m} / \mathrm{s}$ \\
\cline { 2 - 4 } & Presence & 0.5 & $42 \mathrm{~m} / \mathrm{s}$ \\
\hline $\begin{array}{c}\text { Orthogonal } \\
\text { direction }\end{array}$ & Absence & 0.08 & $7 \mathrm{~m} / \mathrm{s}$ \\
\cline { 2 - 4 } & Presence & 0.12 & $10 \mathrm{~m} / \mathrm{s}$ \\
\hline Vertical direction & - & - & $5 \mathrm{~m} / \mathrm{s}$ \\
\hline
\end{tabular}

Table 5: The ratio of the wind speed to the train velocity at each pantograph in the tunnel A.

\begin{tabular}{|c|c|c|c|c|c|}
\hline $\begin{array}{c}\text { Oncoming } \\
\text { train }\end{array}$ & Train set & $\begin{array}{c}\text { No. 1 } \\
\text { pantograph }\end{array}$ & $\begin{array}{c}\text { No. 2 } \\
\text { pantograph }\end{array}$ & $\begin{array}{c}\text { No. 3 } \\
\text { pantograph }\end{array}$ & $\begin{array}{c}\text { No. 4 } \\
\text { pantograph }\end{array}$ \\
\hline \multirow{3}{*}{ Absence } & A & 0.27 & - & - & - \\
\cline { 2 - 6 } & $\mathrm{B}$ & 0.22 & 0.21 & - & - \\
\cline { 2 - 6 } & $\mathrm{C}$ & 0.14 & 0.15 & 0.21 & - \\
\cline { 2 - 6 } & $\mathrm{D}$ & 0.14 & 0.15 & 0.21 & 0.19 \\
\hline Presence & & \multicolumn{5}{|c}{ Maximum 0.45} \\
\hline
\end{tabular}


Table 6: The ratio of the wind speed to the train velocity at each pantograph in the tunnel B.

\begin{tabular}{|c|c|c|c|c|c|}
\hline $\begin{array}{c}\text { Oncoming } \\
\text { train }\end{array}$ & Train set & $\begin{array}{c}\text { No. 1 } \\
\text { pantograph }\end{array}$ & $\begin{array}{c}\text { No. 2 } \\
\text { pantograph }\end{array}$ & $\begin{array}{c}\text { No. 3 } \\
\text { pantograph }\end{array}$ & $\begin{array}{c}\text { No. 4 } \\
\text { pantograph }\end{array}$ \\
\hline \multirow{4}{*}{ Absence } & $\mathrm{A}$ & 0.28 & - & - & - \\
\cline { 2 - 6 } & $\mathrm{B}$ & 0.24 & 0.26 & - & - \\
\cline { 2 - 6 } & $\mathrm{C}$ & 0.18 & 0.20 & 0.22 & - \\
\cline { 2 - 6 } & $\mathrm{D}$ & 0.18 & 0.20 & 0.21 & 0.17 \\
\cline { 2 - 6 } & $\mathrm{E}$ & 0.18 & 0.24 & - & - \\
\hline
\end{tabular}

Table 7: The head wind at the pantograph to be considered (the viewpoint of the pantograph on the running train).

\begin{tabular}{|c|c|c|c|}
\hline $\begin{array}{c}\text { Oncoming } \\
\text { train }\end{array}$ & Cross-section & $\begin{array}{c}\text { The ratio of the } \\
\text { wind speed to } \\
\text { train velocity }\end{array}$ & $\begin{array}{c}\text { Increase ratio of upward force } \\
\text { (when upward force is } \\
\text { proportional to the square of the } \\
\text { wind speed) }\end{array}$ \\
\hline Absence & Standard & 1.3 & 1.69 \\
\cline { 2 - 4 } & Small & 1.2 & 1.44 \\
\hline Presence & - & 1.5 & 2.25 \\
\hline
\end{tabular}

In the case of the presence of the oncoming train in the tunnel, it is necessary to consider the head wind speed 1.5 times as large as the train velocity. Corresponding to these wind speed increase, it is necessary to consider the increasing rate of the upward force of the pantograph. In case where the detail study of current collection performance at each pantograph should be executed, it may be possible to calculate the upward force by referring to the ratios given in tables 5 and 6.

\section{Behavior of overhead contact line}

\subsection{Contact wire uplift and strain at the supporting point}

Fig. 8(a) shows the measured data of the contact wire uplift at the supporting point in the tunnel A. Comparing the measured data for the train D in case of presence and those in case of absence of the oncoming train, uplift in the presence of the oncoming train is greater than that in the absence. The fact confirms that the upward force increases in the presence of the oncoming train. The difference among the measured data for respective train sets is considered to be due to the difference of the head wind speed and the upward force coefficient of each pantograph. The maximum uplift is about $50 \mathrm{~mm}$ in the tunnel A, and about $60 \mathrm{~mm}$ in the tunnel B.

Fig. 8(b) shows the measured data of the strain of the contact wire at the supporting point in the tunnel A. For the train D, the strain has a tendency to 
increase when there is the oncoming train in the tunnel. The uplift indicates similar tendency.

\subsection{Behavior of overhead contact line system}

Table 8 reports the maximum values of the main measured items. The uplift at the supporting point and the decrease of distance between the contact wire and the auxiliary catenary will not raise any issues from the viewpoint of safety and maintenance in view of the current specifications of metal fittings. The decrease of the axial force in the hanger and the dropper is caused by passage of the pantograph. It has some margins in comparison with the strength of material. The maximum displacement of the contact wire is about $20 \mathrm{~mm}$. The maximum angle is 4 degrees. The maximum wind speed in the direction orthogonal to track line is about $10 \mathrm{~m} / \mathrm{s}$. Therefore, behavior of the overhead contact line in the orthogonal direction is also considered not to raise any issue.

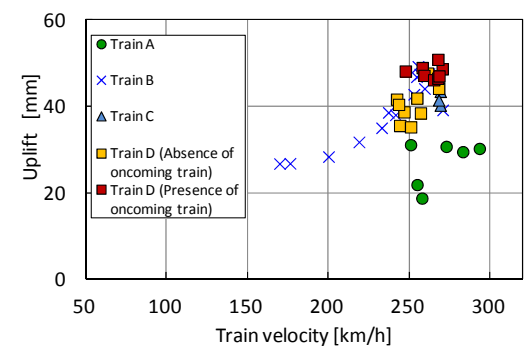

(a) uplift

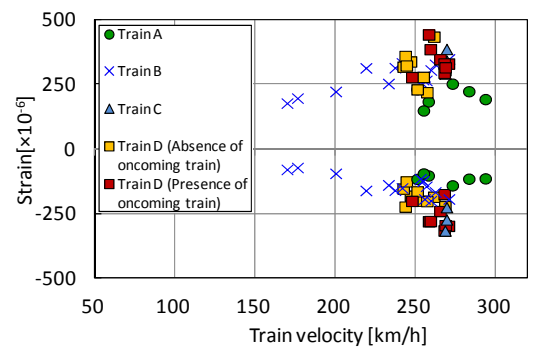

(b) strain

Figure 8: The maximum of contact wire uplift and strain at supporting point.

Table 8: The maximum values of the main measured items.

\begin{tabular}{|c|c|c|c|}
\hline Measured item & Measurement position & Tunnel A & Tunnel B \\
\hline \multirow{2}{*}{ uplift } & Contact wire & $51 \mathrm{~mm}$ & $62 \mathrm{~mm}$ \\
\cline { 2 - 4 } & Auxiliary & $39 \mathrm{~mm}$ & $46 \mathrm{~mm}$ \\
\hline \multirow{2}{*}{$\begin{array}{c}\text { Decrease of } \\
\text { distance between } \\
\text { contact wire and } \\
\text { auxiliary }\end{array}$} & At Final hanger & - & $11 \mathrm{~mm}$ \\
\cline { 2 - 4 } & At No. 1 hanger & $22 \mathrm{~mm}$ & $9 \mathrm{~mm}$ \\
\cline { 2 - 4 } & At No. 4 hanger & $13 \mathrm{~mm}$ & $7 \mathrm{~mm}$ \\
\hline \multirow{2}{*}{$\begin{array}{c}\text { Change of axial } \\
\text { force }\end{array}$} & At O type connector & $29 \mathrm{~mm}$ & - \\
\cline { 2 - 4 } & No. 1 hanger & $-57 \mathrm{~N}$ & $-62 \mathrm{~N}$ \\
\cline { 2 - 4 } & No. 4 hanger & $-60 \mathrm{~N}$ & $-38 \mathrm{~N}$ \\
\hline
\end{tabular}




\section{Forecast of behavior of the overhead contact line by simulation}

\subsection{Simulation conditions}

Using the upward force increase rate shown in table 7 and the dynamic simulation program of pantograph-catenary system [3], we forecast the performance of the current collecting system in the tunnel when the train velocity is increased. The characteristic values of the pantograph such as the upward force coefficient are the values corresponding to the pantographs of the train sets shown in table 2. The conditions of the overhead contact line are shown in table 1. Depending on the combinations of the pantographs and the overhead contact lines, the maximum train velocity is set at a value from $280 \mathrm{~km} / \mathrm{h}$ up to $360 \mathrm{~km} / \mathrm{h}$.

\subsection{The contact wire uplift and strain at hi-speed}

Figs 9 and 10 show the train velocity characteristic of the contact wire uplift and strain respectively at supporting point. They are the values at the supporting point for the train A pantograph. The wind speed 1.0 times is equal to the head wind speed of the pantograph when the train runs in the open air. The larger the head wind of pantograph, the more both the uplift and strain increases. Especially under the condition of presence of the oncoming train in the tunnel (wind speed 1.5 times), the margin will decrease if the train velocity is increased.

Fig. 11 shows train velocity characteristic of the maximum values of contact wire uplift and strain in the span. The overhead contact line system in the tunnel A and the condition of the pantograph on the train D are used in the simulation. Under the condition of presence of the oncoming train in the tunnel, the contact wire uplift is notably increased. The strain is very large at $280 \mathrm{~km} / \mathrm{h}$. The reason of it is that there is no margin of hanger head loop because the distance between the contact wire and the auxiliary catenary at the hanger is decreased. Therefore, such metal fittings as a larger margin of contact wire uplift and a bigger hanger head loop should be used.

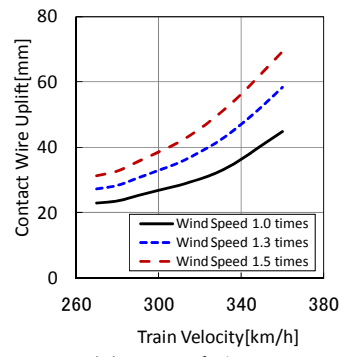

(a) tunnel $\mathrm{A}$

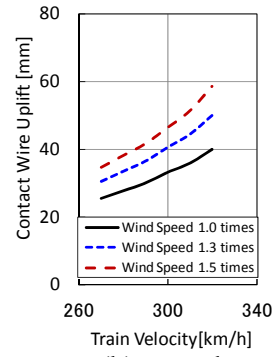

(b) tunnel B

Figure 9: The characteristic of the train velocity and contact wire uplift at the supporting point. 


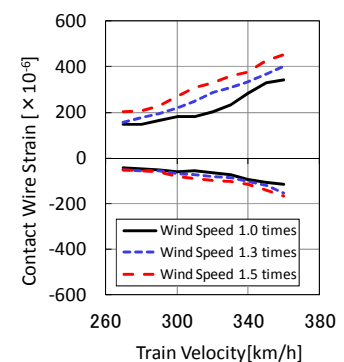

(a) tunnel A

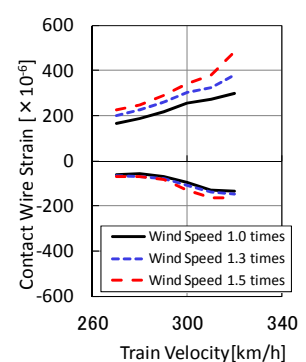

(b) tunnel B

Figure 10: The characteristic of the train velocity and contact wire strain at the supporting point.

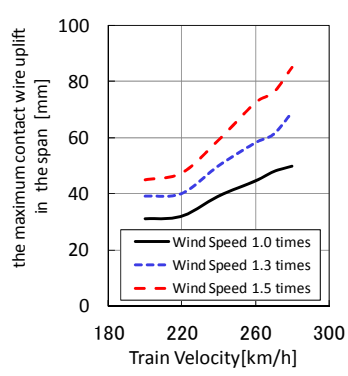

(a) uplift

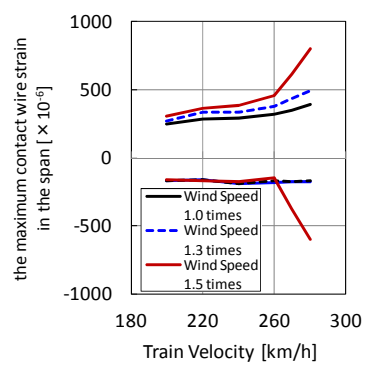

(b) strain

Figure 11: The characteristic of the train velocity and maximum value of contact wire uplift and strain in the span.

\section{Conclusion}

With due consideration the recent speed up of Shinkansen trains, we measured the wind speed and the direction near the overhead contact line system, behavior of the overhead contact line system such as displacement and stress of lines and metal fittings. Using the measured wind speed, we estimated upward force of the pantograph on the running train in the tunnel. Finally, we simulated the current collecting performance of pantograph at high speed of Shinkansen. These results are summarized as follows:

1. The increase of head wind speed in the Shinkansen tunnel is about 0.3 times as large as train velocity in case of absence of the oncoming train, and about 0.5 times in case of presence.

2. The increase of wind speed in the orthogonal direction to the track in the tunnel is about 0.08 times as large as train velocity in case of absence of the oncoming train, and about 0.12 times in case of presence.

3. The head wind speed at the pantograph decreases when the train cross-section is small. The larger the distance from the train head to No. 1 pantograph, the higher the head wind speed is. 
4. Behavior of the overhead contact line system does not raise any issue from the viewpoint of safety and maintenance, under the condition of the current facilities and pantograph at the current commercial operation speed.

5. We estimated that the margins of the strain of contact wire, uplift at the supporting point, and hanger head loop are decreased when the commercial operation speed is increased.

\section{References}

[1] Ikeda, M., et al., Direction and Velocity Characteristics of Air Flow around Pantograph of Running Train. RTRI Report, Vol. 25, No. 6, pp. 11-16, 2011 (in Japanese).

[2] Kajiyama, H., et al., Numerical Calculation of Air Flow in Underground Railway. RTRI Report, Vol. 7, No. 7, pp. 51-58, 1993 (in Japanese).

[3] Aboshi, M., Estimation Method of Contact Line Unevenness using Dynamic Simulation. IEEJ Journal of Industry Applications, Vol. 126, No. 7, pp. 983-988, 2006 (in Japanese). 